Original Research Paper

\title{
Sosialisasi Rumah Bibit Model Kebun Gizi Pada Kelompok Roo Jao Mandiri Sebagai Strategi Ketahanan Pangan Keluarga Di Kelurahan Jatiwangi Kota Bima
}

\author{
${\text { Nurfadhilah } \text { Nadiyah }^{1 *} \text {, Nurul Aisyah }}^{2}$, Nurwahdania $^{3}$ \\ 1,2,3 Program Studi Pendidikan Guru Biologi, Fakultas Keguruan dan Ilmu Pendidikan, Universitas Mataram, \\ Mataram, Indonesia
}

DOI: https://doi.org/10.29303/jpmpi.v3i2.535

Sitasi: Nadiyah, N., Aisyah, N., \& Nurwahdania (2021). Sosialisasi Rumah Bibit Model Kebun Gizi Pada Kelompok Roo Jao Mandiri Sebagai Strategi Ketahanan Pangan Keluarga Di Kelurahan Jatiwangi Kota Bima. Jurnal Pengabdian Magister Pendidikan IPA, 4(1)

Article history

Received: 15 Desember 2020

Revised: 28 Desember 2020

Accepted: 07 Januari 2020

*Corresponding Author:

Nurfadhilah Nadiyah, Program

Studi Pendidikan Biologi,

Fakultas Keguruan dan Ilmu

Pendidikan, Universitas

Mataram, Mataram, Indonesia Email:

dilanadiyah@gmail.com

\begin{abstract}
Abstrak: Kebun gizi merupakan program berbasis masyarakat sebagai upaya pemenuhan kebutuhan buah dan sayur dengan memanfaatkan lahan pekarangan maupun media lain. Program ini bertujuan dalam upaya untuk meningkatkan dan mencukupi kebutuhan gizi masyarakat maka perlu mengoptimalkan dan memanfaatkan pekarangan dan lahan kosong untuk ditanami menjadi kebun gizi sehingga dapat mencukupi kebutuhan gizi masyarakat. Proses pengumpulan data dilakukan dengan cara wawancara dan melakukan pengamatan langsung di lapangan. Data kemudian dianalisis secara deskriptif dan data disajikan secara deskriptif dengan gambar atau foto dari rumah bibit kebun gizi di kelurahan Jatiwangi. Kegiatan ini dilakukan dalam 2 tahap. Tahap pertama dimulai dengan melakukan penyemaian tanaman (sayur, buah dan obat). Tahap kedua merupakan tahap perawatan dimana tanaman yang mulai dibibit dirawat agar tumbuh dengan baik.
\end{abstract}

Kata Kunci: Kebun Gizi; Rumah Bibit; Jatiwangi

\section{Pendahuluan}

Kelurahan Jatiwangi merupakan kelurahan yang terletak di wilayah kecamatan Asakota, Kota Bima yang dibagaian timurnya berbatasan langsung dengan kelurahan Jatibaru dan Matakando, bagian selatan berbatasan dengan kelurahan Santi dan kelurahan Nae, dibagian barat berbatasan dengan kelurahan dan Melayu dan dibagian utara berbatasan langsung dengan Kelurahan kolo. Luas wilayah kelurahan
Jatiwangi adalah 1.735 hektar sedangkan jumlah penduduk sebanyak 9.672 jiwa dengan jumlah kepala keluarga sebanyak 2332.

Kebun gizi merupakan program berbasis masyarakat sebagai upaya pemenuhan kebutuhan buah dan sayur

dengan memanfaatkan lahan pekarangan maupun media lain. Kebun gizi diimplementasikan pertama kali di wilayah Pleret, Bantul, Yogyakarta dan memperoleh penghargaan MDGs award tahun 2014 (Kurniasih dan Adianto, 2018). Rumah bibit kebun gizi adalah bangunan berukuran 4-6 meter 
yang di bangun di atas lahan kosong milik pemerintah kelurahan Jatiwangi yang menjadi program pemerintah dari dinas ketahan pangan provinsi NTB. Kelurahan Jatiwangi menjadi salah satu kelurahan yang menerima bantuan berupa bibit tanaman baik tanaman obat dan tanman sayur, alat-alat perkebunan dan pupuk dari pemerintah melalui program Rumah Zakat. Pemanfaatan dari rumah bibit kebun gizi ini dikelola oleh kelompok Ro'o Jao Mandiri.

Faktor utama perwujudan program KRPL adalah bahwa ketahanan pangan nasional dimulai dari bawah, yaitu dimana rumah tangga merupakan objek dasar acuan terbentuknya konsep ketahanan pangan. Bila satu rumah tangga dapat mengantisipasi pemenuhan kebutuhan pangan secara mandiri dan dapat mengkonsumsi pangan yang beragam, maka prinsip perubahan pola konsumsi masyarakat Indonesia dapat mengindikasikan terbentuknya ketahanan pangan yang berkembang secara signifikan, mandiri dan dapat mengurangi kuota impor akan beras. Salah satu fungsi pengembangan ketahanan pangan itu sendiri, selain dari segi ekonomi rumah tangga, adalah fungsi adanya upaya dalam kontek pemenuhan kebutuhan gizi masyarakat, khususnya kalangan menengah ke bawah. Dengan adanya pola konsumsi beragam dan tidak hanya mengutamakan beras sebagai makanan wajib diharapkan gizi yang diberlakukan sehingga sumberdaya manusia terbentuk ideal (Faqih, 2020).

Berdasarkan hal tersebut, dalam upaya meningkatkan dan mencukupi kebutuhan gizi masyarakat maka perlu mengoptimalkan dan memanfaatkan pekarangan dan lahan kosong untuk ditanami menjadi kebun gizi sehingga dapat mencukupi kebutuhan gizi masyarakat.

\section{Metode}

1. Waktu dan tempat

Program ini dilakukan di Kelurahan Jatiwangi Kecamatan Asakota Kota Bima Nusa Tenggara Barat pada bulan Desember s/d Januari 2020.

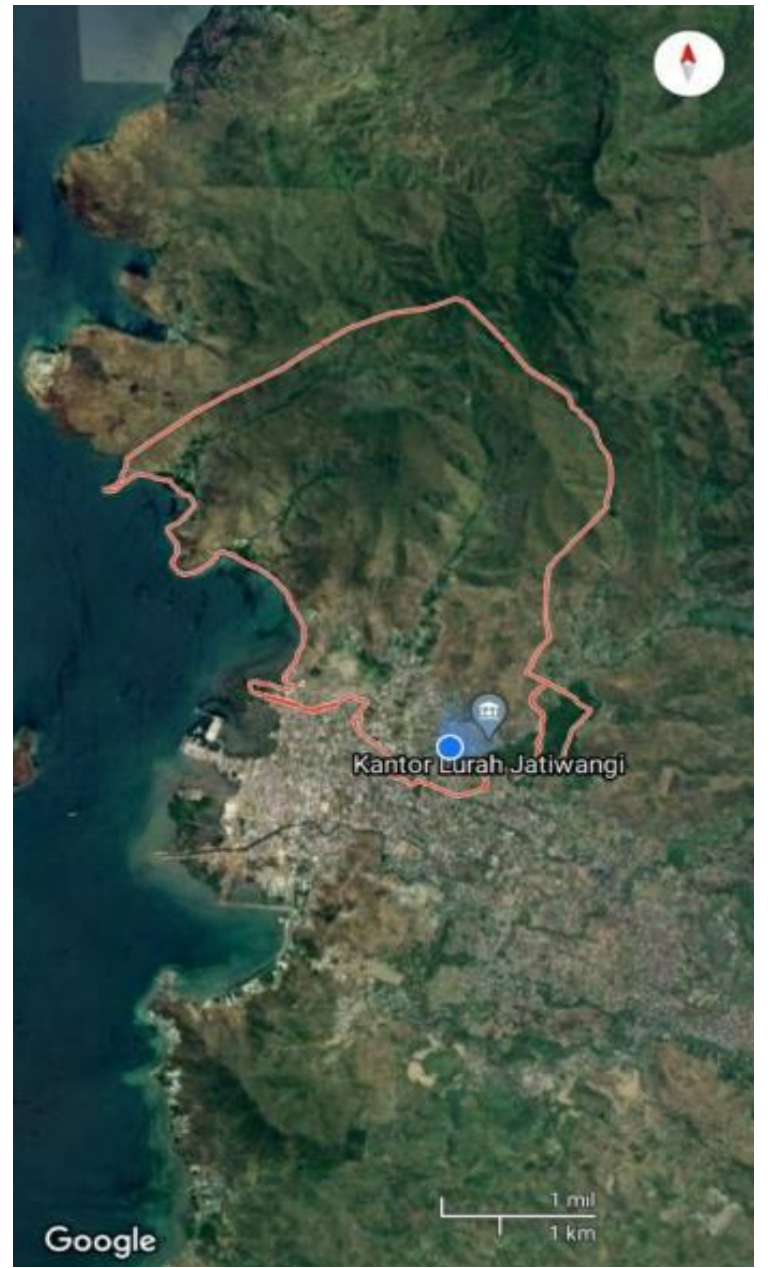

Gambar 1. Kelurahan Jatiwangi

2. Alat dan bahan

Bahan yang dibutuhkan dalam program ini berupa bibit tanaman (sayur, buah dan obat), air dan pupuk kompos. Alat yang digunakan dalam program ini adalah rumah bibit, seperangkat alat berkebun (sekop, polybag, tray semai dan alat semprot tanaman).

3. Bentuk kegiatan

Bentuk kegiatan dalam program pendampingan dalam mengembangkan rumah bibit kebun gizi di kelurahan Jatiwangi adalah 1) Koordinasi dengan perangkat desa/kelurahan, 2) Penentuan lokasi lahan yang strategis, 3) pelaksanaan program kebun gizi yang dimulai dengan penanaman bibit tanaman (sayur, buah dan obat), 4) Pendampingan program kebun gizi, 5) Evaluasi pelaksanaan program kebun gizi. 


\section{Metode}

Metode yang digunakan dalam pelaksanaan rumah bibit kebun gizi ini meliputi sosialisasi kegiatan dan perencanaan, diskusi ataupun ceramah dan melakukan demonstrasi kegiatan secara langsung kepada masyarakat. Metode sosialisasi dilakukan untuk mengenalkan kegiatan yang akan dilakukan dengan tujuan untuk membuka dan menambah wawasan masyarakat terkait ilmu tentang rumah bibit kebun gizi. Metode diskusi dilakukan untuk menampung dan menjawab pertanyaan dari masyarakat terkait masalah dan penerapan kegiatan. Sebagai bentuk aplikasi kegiatan, demonstrasi kegiatan harus dilakukan untuk lebih memberikan pemahaman dan memberikan masyarakat ruang untuk melakun secara langsung seperti demo penerapan. Proses pengumpulan data dilakukan dengan cara wawancara dan melakukan pengamatan langsung di lapangan. Data kemudian dianalisis secara deskriptif dan data disajikan secara deskriptif dengan gambar atau foto dari rumah bibit kebun gizi di kelurahan Jatiwangi.

\section{Hasil dan Pembahasan}

Program sosialisasi rumah bibit kebun gizi pada kelompok Roo Jao Mandiri di Kelurahan Jatiwangi Kecamatan Asakota Kota Bima dalam rangka pemberdayaan masyarakat desa dilakukan secara terstruktur dan melibatkan masyarakat secara langsung seperti kelompok Ro'o Jao Mandiri dan warga kelurahan Jatiwangi secara umum. Program pendampingan masyarakat dalam mengembangkan rumah bibit kebun gizi ini bertujuan untuk mengelola bantuan dari pemerintah melalui program rumah zakat oleh dinas ketahanan pangan dalam program peningkatan ketahanan pangan masyarakat dengan memanfaatkan pekarangan dan lahan terbengkalai.

1. Koordinasi dengan perangkat desa

Koordinasi dengan perangkat desa diperlukan sebagai langkah awal dalam melakukan sosialisasi kepada masyarakat yang berada di lingkungan kelurahan Jatiwangi Asakota Kota Bima. Koordinasi dilakukan bersama lurah Jatiwangi beserta perangkat lurah.

Koordinasi yang dilakukan kemudian menghasilkan beberapa keputusan yaitu :

a. KKN dilakukan di Lingkungan Tato RT 007/RW 003 Kelurahan Jatiwangi.

b. Anggaran dalam pengelolaan rumah bibit kebun gizi semua ditanggung oleh pemerintah kelurahan.

c. Pada tanggal 27 November 2020 kelompok Roo Jao Mandiri Penerimaan bantuan berupa bibit dan alat berkebun lainnya dari pemerintah melalui program Rumah Zakat oleh Dinas Ketahanan Pangan.

d. Bibit yang telah dipindahkan ke media tanam yang lebih besar kemudian akan dibagikan kepada masyarakat di sekitar lingkungan Tato dengan biaya administrasi sebesar Rp. 1000,- per polybag.

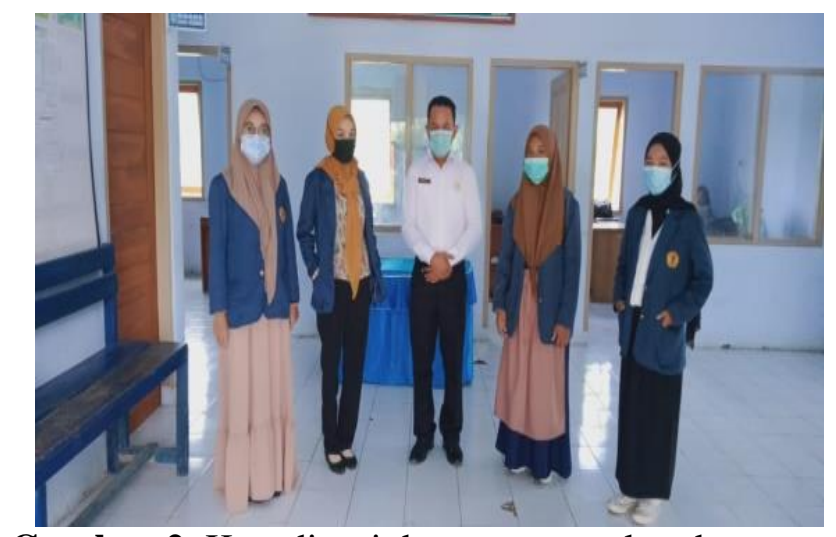

Gambar 2. Koordinasi dengan perangkat desa

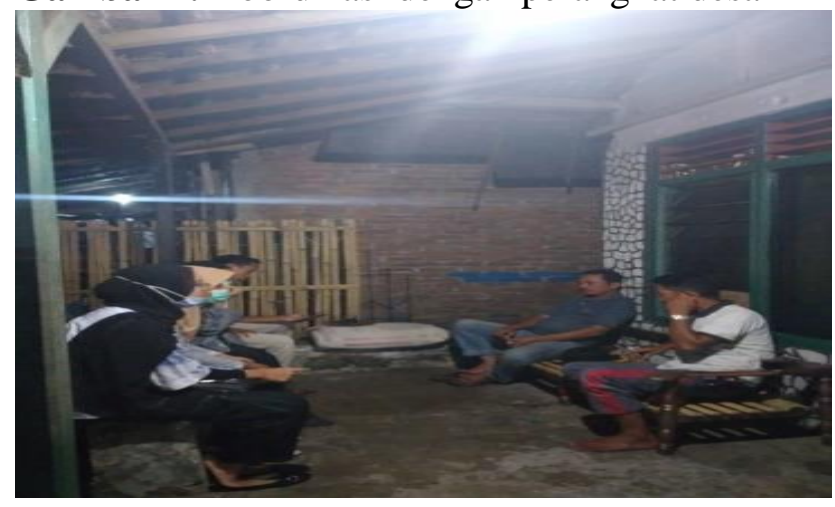

Gambar 3. Diskusi bersama perangkat desa 
2. Penentuan Lokasi

Penentuan lokasi dilakukan untuk memperjelas arah dan juga untuk membatasi lingkup yang akan dilakukan sebagai penanaman serta pembibitan tanaman. Lokasi tersebut berada di lingkungan Tato, RT 007 RW 003 kelurahan Jatiwangi Kota Bima. Pada lokasi inilah green house dibangun sebagai Rumah bibit kebun gizi.

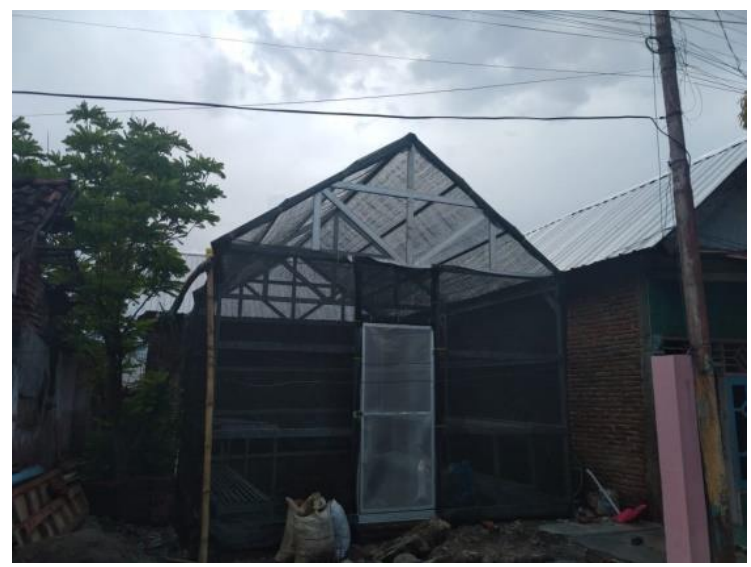

Gambar 4. Rumah bibit kebun gizi

3. Penyemaian

Sebelum menjadi bibit benih dari tanaman sayur dan tanaman buah perlu di semai terlebih dahulu. Penyemaian dilakukan untuk menyeleksi bibit yang sudah tumbuh dan kuat untuk ditanam pada lahan yang lebih luas. Penyemaian biasa dilakukan dalam stray semai yang berukuran $54 \mathrm{~cm} \mathrm{x}$ $28 \mathrm{~cm}$ x $5 \mathrm{~cm}$. Stray semai ini kemudian di isi dengan media tanam berupa pupuk kompos.

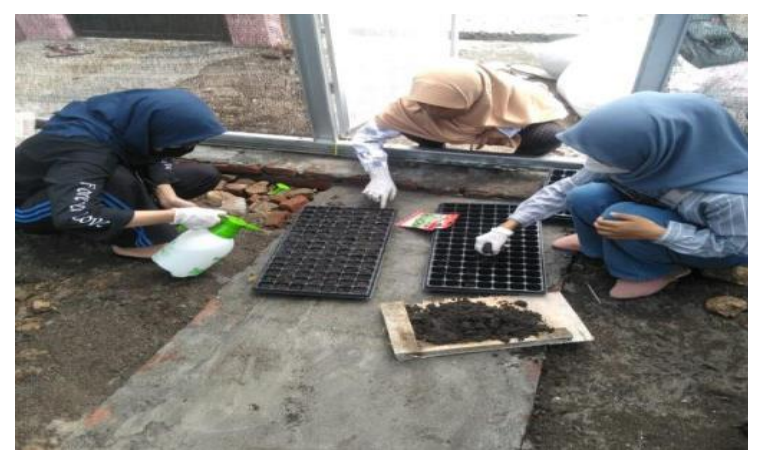

Gambar 5. Proses penyemaian

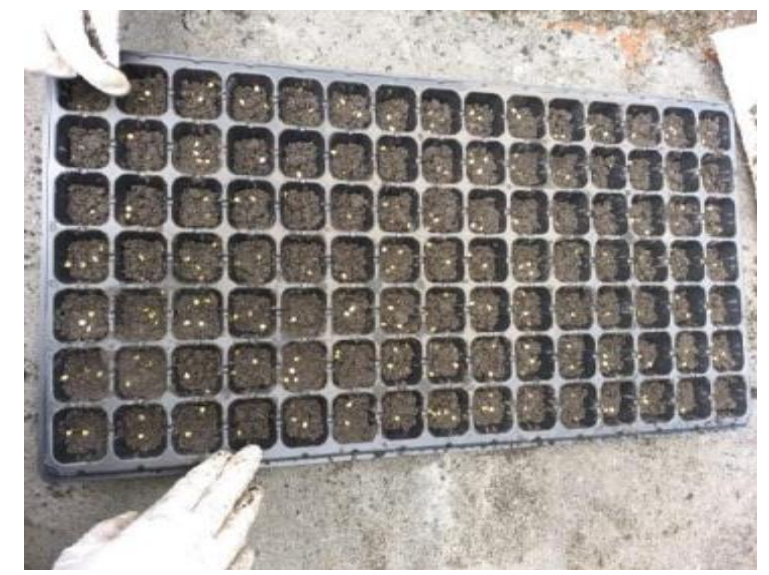

Gambar 6. Penyebaran bibit

Tanaman obat dapat dibudidayakan dengan mudah dan umumnya memiliki fungsi ganda, misalnya untuk tanaman pangan, tanaman hias, tanaman bumbu masak dan tanaman buahbuahan, sehingga sangat menguntungkan jika ditanam di pekarangan (Sumiastri dan Cahyani, 2011). Hasil dari budidaya tanaman obat tersebut dapat digunakan sebagai edukasi tanaman herbal atau tanaman obat tradisional kepada anggota keluarga, dikonsumsi sebagai tindakan menjaga kesehatan tubuh dan salah satu tindakan nyata penghijauan tanaman. Sumarmiyati dan Rahayu (2015) menyatakan bahwa obat tradisional adalah obat-obatan yang diolah secara tradisional, turuntemurun, berdasarkan resep nenek moyang, adatistiadat, kepercayaan, atau kebiasaan setempat, baik bersifat magic maupun pengetahuan tradisional.

Menurut penelitian masa kini, obatobatan tradisional memang bermanfaat bagi kesehatan, dan kini digencarkan penggunaannya karena lebih mudah dijangkau masyarakat, baik harga maupun ketersediaannya. Obat tradisional pada saat ini banyak digunakan karena menurut beberapa penelitian tidak terlalu menyebabkab efek samping, karena masih bisa dicerna oleh tubuh Kegiatan budidaya tanaman obat di polybag diharapkan dapat memotivasi, meningkatkan pengetahuan dan keterampilan ibuibu rumah tangga dalam pemanfaatan lahan kosong atau pekarangan. Penerapan teknik budidaya dalam polibag yang tergolong sederhana diharapkan dapat diterima dengan mudah oleh ibu-ibu rumah tangga. Hasil dari budidaya ini dapat dimanfaatkan sebagai obat dan 
bumbu dapur, serta meningkatkan perekonomian rumah tangga (Dewi dan Ida, 2019).

Pembibitan tanaman obat dilakukan dengan cara menanam tunas langsung pada polybag dengan mengguanakan media berupa campuran tanah dan kompos dengan perbandingan 3:1.

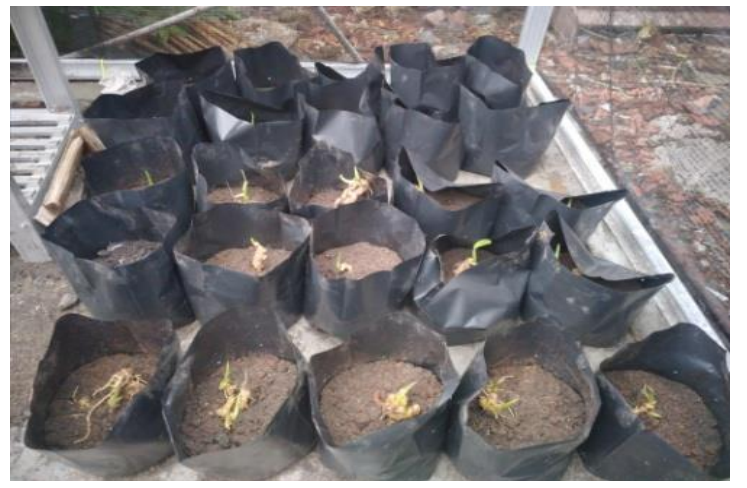

Gambar 7. Bibit tanaman obat

4. Perawatan

Faktor utama yang mempengaruhi pertumbuhan bibit tanaman adalah iklim yang meliputi suhu udara, radiasi sinar matahari, angin, dan kelembaban. Faktor kedua adalah tanah dan kandungan unsur hara yang ada pada tanah. Faktor ketiga adalah biotik, seperti gulma, hama, dan penyakit tanaman. Cahaya matahari merupakan sumber energi bagi tanaman dan merupakan salah satu unsur iklim yang memegang peranan penting dalam menentukan pertumbuhan dan perkembangan tanaman. Di daerah tropis seperti di Indonesia, intensitas cahaya dan suhu udara yang tinggi merupakan masalah yang banyak dihadapi dalam budidaya tanaman introduksi dari daerah subtropis (Firmansyah dkk, 2009). Perawatan bibit tanaman di rumah bibit dilakukan dengan cara menyiram tanaman dengan air dengan tujuan untuk menjaga kelembapan tanah. Pada proses pembibitan, bibit tanaman langsung ditanam pada tray yang sudah berisi pupuk kompos sehingga nutrisi yang diperlukan oleh bibit tetap terpenuhi. Agar benih yang ditanam berhasil tumbuh dengan baik maka penyemaian perlu dilakukan di tempat yang terhindar dari sinar matahari langsung, terpaan angin dan derasnya hujan. Oleh karena itu, maka penanaman bibit dilakukan di dalam rumah bibit kebun gizi.
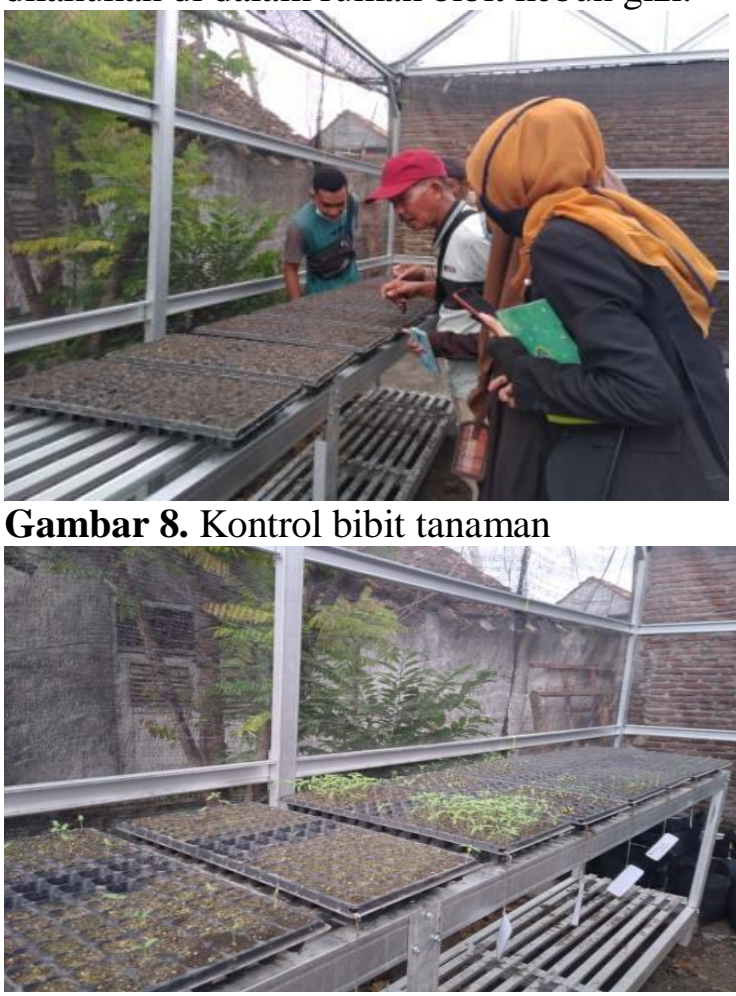

Gambar 9. Tanaman buah dan sayur yang telah berusia 2 minggu

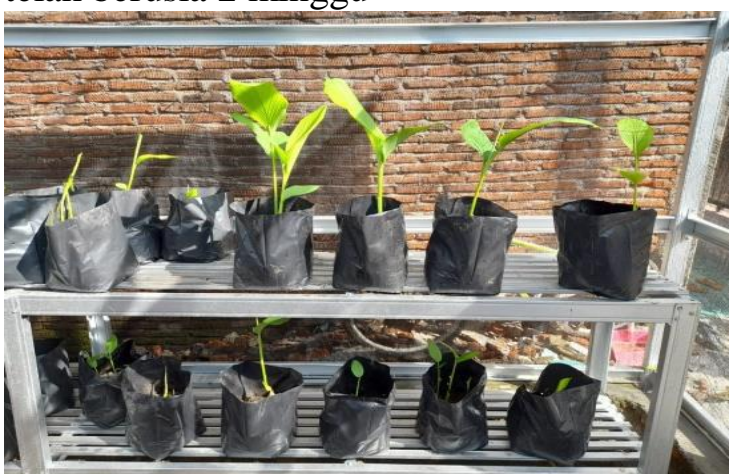

Gambar 10. Tanaman obat yang telah berusia 2 minggu

\section{Kesimpulan}

Berdasarkan hasil pengamatan yang dilakukan dalam program pendampingan masyarakat dalam mengembangkan rumah bibit kebun gizi maka dapat di simpulkan bahwa kegiatan ini melibatkan masyarakat secara langsung. Kegiatan ini dimulai dengan melakukan persiapan lahan, pembibitan dan 
perawatan. Pemahaman masyarakat mengenai budidaya tanaman pangan dan pemanfaatan lahan yang tidak terpakai sudah lebih baik dengan adanya kegiatan pendampingan. Diperlukan pengembangan mengenai jenis bibit yang lebih berfariasi agar dapat mengembangkan kebun gizi untuk keburtuhan ekonomi masyarakat yang ada di kelurahan Jatiwangi.

\section{Daftar Pustaka}

Dewi, Prita Sari dan Ida Widiyawati. (2019). Pengenalan Teknologi Budidaya Tanaman Obat sebagai Upaya Pemanfaatan Lahan Pekarangan di Kelurahan Pabuwaran Purwokerto, Jawa Tengah. Jurnal Panrita Abdi. 3 (2): 105112.

Faqih, Achmad. (2020). Pemberdayaan Perempuan Melalui Pemanfaatan Dan Penataan Pekarangan. ABDIMAS GALUH. 2 (1): 1-11.

Firmansyah, Ferry., Tino M. Anngo dan Aos M Akyas. (2009). Pengaruh Umur Pindah Tanam Bibit dan Populasi Tanaman terhadap Hasil dan Kualitas Sayuran Pakcoy (Brassica campestris L., Chinensis group) yang Ditanam dalam Naungan Kasa di Dataran Medium. Jurnal Agrikultura. 20(3): 216-224.

Kurniasih, Dwi Endah dan Joko Adianto. (2018). Kebun gizi sebagai strategi berbasis masyarakat untuk memenuhi kebutuhan konsumsi. Berita Kedokteran Masyarakat. 34 (2): 93-97.

Sumarmiyati, Sumarmiyati dan Rahayu, S.W.P. (2015). Potensi Pengembangan Tanaman Obat Lokal Skala Rumah Tangga untuk Mendukung Kemandirian Pangan dan Obat di Samarinda, Kalimantan Timur. Prosiding Seminar Nasional Masyarakat Biodiversitas Indonesia. 1 (2): 330-336.

Sumiastri, Priadi, N. D. dan Cahyani Y. (2011). Variasi Jenis Tanaman Obat dalam Upaya Penggalakan TOGA di Pekarangan Desa Cangkring, Jember. Penelitian Hayati: 39-43. 